\title{
Loss of IL-10 secretion by regulatory B lymphocytes in multiple sclerosis patients
}

\author{
Laure Michel ${ }^{1,2^{*}}$, Nicolas Degauque ${ }^{1}$, Alexandra Garcia', Marion Salou', Annie Elong Ngono', Jean-Paul Soulillou', \\ David Laplaud ${ }^{1,2}$, Sophie Brouard ${ }^{1}$
}

From 6th European Workshop on Immune-Mediated Inflammatory Diseases

Nice, France. 23-25 November 2011

\section{Background}

Recently, an alternative role of B cells has emerged. Regulatory B cells have been shown to down-regulate immune responses in mice and humans. These cells control disease progression in several models of human autoimmune diseases, including a model of Multiple Sclerosis (MS). Their regulatory function mostly relies on their capacity to produce IL-10.

\section{Objectives}

Our aim was to explore the frequency, the phenotype and the functional properties of regulatory B cells in MS patients compared to Healthy Volunteers (HV).

\section{Methods}

All patients suffered from MS and had not received immune drugs since at least 6 months. The frequency and the phenotype of $B$ cell subsets have been analysed using different specific markers: $\mathrm{CD} 19^{+} \mathrm{CD} 27^{+}$memory B cells, $\mathrm{CD} 19^{+} \mathrm{CD} 38^{\mathrm{dim}} \mathrm{CD} 24^{\mathrm{dim}}$ mature naïve $\mathrm{B}$ cells and $\mathrm{CD} 19^{+}$ CD24 ${ }^{\text {high }} \mathrm{CD} 38^{\text {high }}$ transitional B cells. Their capacity to secrete IL-10 was analysed in vitro 48 hours after stimulation by CD40 ligand and CpG ODN.

\section{Results}

Thirty-eight MS patients (mean age: $41.55 \pm 12.8 \mathrm{yrs}$ ) and $21 \mathrm{HV}$ (mean age: $35.4 \pm 13.4$ yrs, NS) have been included. The patients had different MS forms: Clinically Isolated Syndrome $(n=5)$, Relapsing-Remitting $(n=23)$, Secondary Progressive $(n=4)$ and Primary Progressive $(n=6)$.

No significant difference was found for the frequency of the different B cell subsets in the different subgroups of patients. Particularly, MS patients harbor the same number (in frequency and absolute value) of $\mathrm{CD} 19^{+}$ CD24 ${ }^{\text {high }} \mathrm{CD} 38^{\text {high }}$ transitional B cells. However, the frequency of IL-10 secreting B cells was significantly decreased in MS patients $(0.9 \pm 0.5 \%, \mathrm{n}=9)$ compared to HV $(2 \pm 0.95 \%, \mathrm{n}=10, \mathrm{p}<0.05$, Mann Whitney test).

\section{Discussion/perspectives}

MS patients display the same frequency of CD19+ $\mathrm{CD} 24^{\text {high }} \mathrm{CD} 38^{\text {high }}$ transitional B cells, described as having regulatory properties. Nevertheless, B cells of MS patients present a significant decreased secretion of IL10 , supporting a defect in the B cells regulatory property. If confirmed, these results could have a considerable impact for the development of new therapeutic strategies.

\section{Author details}

${ }^{1}$ INSERM U643, Nantes University, Nantes, France. ${ }^{2}$ Neurology Dept., Nantes Hospital, Nantes, France.

Published: 23 November 2011

doi:10.1186/1479-5876-9-S2-P25

Cite this article as: Michel et al:: Loss of IL-10 secretion by regulatory B lymphocytes in multiple sclerosis patients. Journal of Translational Medicine 2011 9(Suppl 2):P25. 